\title{
A Scientometric Study Of Cotton (Gossypium Spp.) Research for (1976-2018)
}

\author{
Rajendran.L \\ Assistant Librarian, Tamil Nadu Veterinary and Animal Sciences University, Madras \\ Veterinary College, Chennai - 600 051, Tamil Nadu, India
}

\begin{abstract}
The Study investigation the examination exercises on cotton (Gossypium spp.), in view of the all out productions yield. The information is recovered from CAB Direct Online Database for a long time (1976-2018). Sorts of archives, language, rank arrangements of journals, most beneficial authors, positioning on nations dependent on their productions yield are displayed.
\end{abstract}

Keywords: Cotton, Gossypium spp., Scientometric, $C A B$ Direct, Agricultural Crop, Calculate Mean Absolute Deviation, M.A.D.

\section{Introduction}

Cotton (Gossypium spp.), a main characteristic fiber, is a noteworthy money crop on the planet and is developed industrially in excess of 50 nations. China, India, Pakistan, USA, and Uzbekistan are the five noteworthy cotton developing nations, with China holding the most astounding efficiency $(1,265 \mathrm{~kg} / \mathrm{ha})$. Cotton is one of the most significant fiber and money harvest of India and plays a prevailing job in the modern and horticultural economy of the nation [7]. It gives the fundamental crude material (cotton fiber) to cotton material industry. Cotton in India gives direct occupation to 6 million ranchers and around 40 - 50 million individuals are utilized in cotton exchange and its preparing. In India, there are ten noteworthy cotton developing states which are isolated into three zones, viz. north zone, focal zone and south zone. North zone comprises of Punjab, Haryana, and Rajasthan. Focal zone incorporates Madhya Pradesh, Maharashtra and Gujarat. South zone includes Andhra Pradesh, Telangana, Karnataka and Tamil Nadu. Other than these ten States, cotton development has picked up energy in the Eastern State of Orissa [4]. Cotton is likewise developed in little zones of non-conventional States, for example, Uttar Pradesh, West Bengal and Tripura.

\section{Objective of the Study}

To analyse the research activities on cotton (Gossypium spp.) based on the total publication output, its growth rate, types of publications, top journals publishing papers on cotton research, most beneficial authors and positioning on nations based on publication output on cotton crop research.

\section{Review of Literature}

Scientometric researches have carried out earlier via considered one of a type author on the one-of-akind individual journal publications and literature on specific issue areas. The following studies related to the targets of this observe were reviewed.

Sozon Papavlasopoulos (2019) studied the extraction of the periodical non-stationarity feature of time series is obtained via the google trend data using keywords from modern sciences. This study aims to investigate when a keyword time series gives non-stationarity pics because this satisfies that the analysis of non-stationary categorical time series yields goodness of fit practice in the prediction issue. This method is implemented via an algorithm which is based on the extraction of the non- stationary distance as well as the formulation of the polynomial regression. The non-stationary algorithm is applied and the statistical evaluation is obtained using the non-parametric Cochran's Q Test. The Q test leads to the conclusion that the Medicine and Biochemistry sciences are ranking in the top of the user's preference followed by Physics, Mathematics and Social Sciences, while the emerging sciences such as Material Science are in the last rank positions. 
Gupta B.M and Dhawan S.M. (2018) have analyzed the Indian output of 4402 papers in robotics research, as indexed in Scopus database during 2007-16, with a view to understand India's growth rate, global share, citation impact, international collaborative papers share, distribution of publications by broad subjects, productivity and in addition discuss the citation profile of top organizations and authors, preferred communication media and characteristics of high cited papers. India registered $24.84 \%$ growth, $2.21 \%$ global publications share, $9.63 \%$ international collaborative publications share, and averaged 4.13 citations per paper during the period. Computer science was the most followed subject for robotics research with $67 \%$ publications share, followed by engineering $(52.34 \%)$, mathematics $(12.81 \%)$, etc. Top 50 productive organizations and authors belong to academic and R\&D sectors and they accounted for $61.93 \%$ and $26.94 \%$ publications share and $70.54 \%$ and $35.48 \%$ citations share in Indian robotics research output. Top 25 most productive journals accounted for $41.38 \%$ share of 1566 journal papers published in robotics research by India. India contributed only 16 highly cited papers with 100 to 368 citations per paper.

\section{Rajendran Lakshmanan (2018) an} examination of the investigation the exploration exercises on Leptospirosis diseases, in light of the aggregate distribution yield. The information is recovered from the $\mathrm{CAB}$ Direct Online Database for a long time (1955-2017). Types of documents, language, rank lists of journals, most productive authors, a ranking of countries based on their publication output are presented.

\section{Ritu Gupta, Dhawan S.M and Gupta B.M} (2016) had said the 7818 world publications on global rabies research, as indexed in Scopus database covering the period 1999-2014. The global rabies research increased by $5.87 \%$ per annum and its citation impact averaged to 14.27 citations per paper. Top 15 most productive countries continued to dominate world rabies research through 1999-2014 both in terms of quality and quantity of research. Together they accounted for as much as $83.82 \%$ share of world total output during 1999-2014. Twelve of these top countries scored relative citation index (RCI) above the world average of 1: USA (1.74), U.K. (1.70), France (1.66), Switzerland (1.62), Germany and Netherlands (1.50 each), Australia (1.44), Japan (1.39), Thailand (1.35), Canada (1.31), South Africa (1.24) and Italy (1.08) during 1999- 2014. Being a multidisciplinary topic, world rabies research is widely scattered across several disciplines. Medicine contributed the largest share $54.80 \%$, followed by 7 other disciplines. The top 20 most productive organizations and authors engaged on rabies research respectively accounted for $40.94 \%$ and $21.42 \%$ share of publications output and $39.62 \%$ and $34.90 \%$ share of world citations during 1999-14. The world rabies research output is highly scattered across journals. Top 20 most productive journals barely accounted for $24.06 \%$ share of global rabies research. Less than 2 per cent of global rabies research papers (148) received 100 plus citations, cumulated 29160 citations, with an average of 197.03 citations per paper. These 148 highly cited papers involved the participation of 1003 authors and 502 organizations and were published in 85 journals. The USA contributed the largest number of highly cited papers (89), followed by U.K. (32), France (20), Germany (11), Canada, Australia and Belgium (7 each), Thailand and Switzerland (6 each), Japan (5), Kenya (4), South Africa, Russia Federation and Tanzania (3 each), etc. For India, rabies research is not a top priority.

Kumaravel J.P.S., Pricilla Rani $P$ and Kalai Selvi S. (2013) had conduct a scientometric analysis of the body of literature on robotic medicine covered by PubMed database for a period from 2000-2011 and identify the quantum of transient and continuant authors. A total of 9906 articles were downloaded from PubMed database using the search term robotics in mesh headings subjected to scientometric data analysis techniques. A number of research questions pertaining to publication frequency, country of publication, individual productivity of authors, continuant, and transient nature of authors were proposed and answered. Based on the findings, many implications emerged that improve one's understanding of the identity of robotic medicine as a distinct biomedical field. The pool of articles is 
drawn from PubMed database only though there are other databases also.

Rajendran Lakshmanan (2018) have demonstrated this paper, attempts to analyze quantitatively the growth and development of Potato (Solanum tuberosum) vegetable crop research in India in publication output as reflected in CAB Direct Online Database. During the period 1939-2017 a total of $1,27,234$ papers were published by the scientists of global respectively on Potato Crop analysis. India is the top country in Agricultural research with its contribution of 7,258 papers which is nearly $(7.66 \%)$ of the global research output of Agricultural research followed by the specific country are in USA with 7,056 papers $(7.45 \%)$. The most preferred journals where the American Potato Journal with 1,784 papers $(1.88 \%)$ followed by the Potato Research with 1,764 papers $(1.86 \%)$. The study revealed that out of the world, India has the highest range the production of Potato. It covers India is a top level in the field of agricultural research as a part of the Indian country are ranked higher position of Uttar Pradesh in a northern region.

\section{Materials and Methods}

The study is based on the publication data on Cotton research, retrieved from the CAB Direct Online database for (1976-2018). Coverage includes leading bibliographic database $\mathrm{CAB}$ abstracts and global health, and databases from internet resources and abstract journals. $\mathrm{CAB}$ Direct provides access to:

- Over 11.5 million bibliographic records

- Over 350,000 full text articles hosted by $\mathrm{CABI}$ and

- Many other authoritative reviews, news articles and reports

CAB Direct has a clean, simple design and a Google like search functionality to enable the users to find what is needed quickly and easily. The Advanced Search facility of CAB Direct Online database was used for this study. The keyword 'Cotton' has been used in article tile field and the search

was performed.

\section{Results and Analysis}

\subsection{Calculate Mean Absolute Deviation (M.A.D) of Research Output}

It is observed from the study that the number of papers has been increased gradually i.e. 29 to 410 papers were published in 2001-2007 and also continuously increased in the year 2008 - 2012 ; because of the research out has been changed in this study [6]. A study of the cotton research output is calculating mean absolute deviation (M.A.D) of overall analyzing the research and development in the field [2]. Table-1 shows that the cotton research output, it is clear that the period has 1980 (1) has less publication in that period, particularly that year was started in research outgrowth in an area, but slowly increasing trend value of that particular period on 2001-2007. Where $\sum$ is a total number of publications: data value obtained from mean divided by number of values. The M.A.D value for the period 1976-2018 is worked out to 4.87 and its calculate the mean is 161.

Table1. Mean Absolute Deviation (M.A.D) of Overall Research Output

\begin{tabular}{|c|c|c|}
\hline Year & $\begin{array}{c}\text { No. Of } \\
\text { Articles }\left(\sum\right)\end{array}$ & $\begin{array}{c}\text { Data Value - } \\
\text { Mean| }\end{array}$ \\
\hline 1976 & 2 & 159 \\
\hline 1977 & 3 & 158 \\
\hline 1978 & 4 & 157 \\
\hline 1979 & 2 & 159 \\
\hline 1980 & 1 & 160 \\
\hline 1981 & 3 & 158 \\
\hline 1982 & 4 & 157 \\
\hline 1983 & 3 & 158 \\
\hline 1984 & 5 & 156 \\
\hline 1985 & 5 & 156 \\
\hline 1987 & 1 & 160 \\
\hline 1988 & 9 & 152 \\
\hline 1989 & 7 & 154 \\
\hline 1990 & 7 & 154 \\
\hline 1992 & 3 & 158 \\
\hline 1993 & 11 & 150 \\
\hline 1994 & 3 & 158 \\
\hline 1995 & 1 & 160 \\
\hline 1996 & 6 & 155 \\
\hline 1997 & 1 & 160 \\
\hline 1998 & 1 & 160 \\
\hline 1999 & 10 & 151 \\
\hline 2000 & 9 & 152 \\
\hline 2001 & 29 & 132 \\
\hline 2002 & 25 & 136 \\
\hline
\end{tabular}




\begin{tabular}{|c|c|c|}
\hline 2003 & 21 & 140 \\
\hline 2004 & 76 & 85 \\
\hline 2005 & 222 & 61 \\
\hline 2006 & 223 & 62 \\
\hline 2007 & 410 & 249 \\
\hline 2008 & 340 & 179 \\
\hline 2009 & 359 & 198 \\
\hline 2010 & 443 & 282 \\
\hline 2011 & 559 & 398 \\
\hline 2012 & 573 & 412 \\
\hline 2013 & 519 & 358 \\
\hline 2014 & 625 & 464 \\
\hline 2015 & 637 & 476 \\
\hline 2016 & 541 & 380 \\
\hline 2017 & 533 & 372 \\
\hline 2018 & 347 & 186 \\
\hline & 6583 & 199.32 \\
\hline
\end{tabular}

The Calculator uses the following formula for calculating the mean absolute deviation:

$$
\frac{1}{\mathrm{n}}=\sum_{\mathrm{n}=1}^{\mathrm{n}} \mid \mathrm{x}_{\mathrm{i}}-\mathrm{m}(\mathrm{x}) \mathrm{I}=\mathrm{M} . \mathrm{A} . \mathrm{D}
$$

$$
\text { M.A.D }=\frac{199.32}{41}=4.87
$$

This calculator uses the following formula to calculate the mean:

$$
\Delta=\frac{1}{n} \sum_{i=1}^{n}\left(x_{i}\right)
$$

$\operatorname{Mean}(\mathrm{A})=161$

\subsection{Positioning on Nations Distribution of} Publications

The study reveals that India is the top country in Agricultural research, with its contribution of 2,177 papers which is nearly $(33.03 \%)$ of the global research output of Agricultural research followed by the specific country are in Pakistan, with 414 papers $(6.29 \%)$ ranks second position, with 246 papers $(3.74 \%)$ in is a third position [4]. It covers India is a top level in the field of Agricultural research, Maharashtra (6.06\%), Northern States are ranked first place in India and it covers $70 \%$ of agricultural lands in India so that mainly concentrate on agriculture orientation[3]. The top 10 Country based on number of publications is furnished in Table -2 .

Table - 2. Positioning on Nations of Cotton Analysis

\begin{tabular}{|l|c|c|c|}
\hline $\begin{array}{c}\text { Name of } \\
\text { the } \\
\text { Country }\end{array}$ & $\begin{array}{c}\text { No. of } \\
\text { Publications }\end{array}$ & Percentage & Rank \\
\hline India & 2177 & 33.03 & 1 \\
\hline Pakistan & 414 & 6.29 & 2 \\
\hline China & 246 & 3.74 & 3 \\
\hline Brazil & 229 & 3.48 & 4 \\
\hline $\begin{array}{l}\text { South } \\
\text { Africa }\end{array}$ & 205 & 3.11 & 5 \\
\hline USA & 195 & 2.96 & 6 \\
\hline Australia & 151 & 2.30 & 7 \\
\hline Turkey & 132 & 2.01 & 8 \\
\hline Egypt & 110 & 1.67 & 9 \\
\hline Iran & 105 & 1.60 & 10 \\
\hline
\end{tabular}

\subsection{Rank Arrangements of Journals}

The most popular journals by the scientists concerned with the Cotton analysis were: Journal of Cotton Research and Development with 954 papers $(14.48 \%)$ followed by the International Journal of Plant Protection with 126 papers $(1.92 \%)$. The study revealed that out of high five most popular journals by the cotton researchers, third place like us journal of Experimental Zoology, India viz., 116 papers (1.76\%) and Acta Entomologic Sinica 98 papers (1.49\%), Egyptian Journal of Biological Pest Control 98 papers $(1.49 \%)$ and ranking which clearly indicates that the contribution of India in cotton analysis is major role [1] it indicates the ranking second position followed by Pakistan. The highest 10 most popular journals are listed in Table- 3 with the amount of papers revealed. 
Table - 3. Rank Arrangements of Journals by Cotton Crop Analysis

\begin{tabular}{|c|c|c|c|}
\hline Sl.No. & Journal Name & $\begin{array}{l}\text { No. Of } \\
\text { Papers }\end{array}$ & Percentage \\
\hline 1. & $\begin{array}{l}\text { Journal of Cotton } \\
\text { Research and } \\
\text { Development }\end{array}$ & 954 & 14.48 \\
\hline 2. & $\begin{array}{l}\text { International } \\
\text { Journal of Plant } \\
\text { Protection }\end{array}$ & 126 & 1.92 \\
\hline 3. & $\begin{array}{l}\text { Journal of } \\
\text { Experimental } \\
\text { Zoology, India }\end{array}$ & 116 & 1.76 \\
\hline 4. & $\begin{array}{l}\text { Acta Entomologice } \\
\text { Sinica }\end{array}$ & 98 & 1.49 \\
\hline 5. & $\begin{array}{l}\text { Egyptian Journal of } \\
\text { Biological Pest } \\
\text { Control }\end{array}$ & 98 & 1.49 \\
\hline 6. & $\begin{array}{l}\text { Madras } \\
\text { Agricultural } \\
\text { Journal }\end{array}$ & 95 & 1.45 \\
\hline 7. & $\begin{array}{l}\text { Pakistan Journal of } \\
\text { Agricultural } \\
\text { Sciences }\end{array}$ & 95 & 1.45 \\
\hline 8. & $\begin{array}{l}\text { Pakistan Journal of } \\
\text { Zoology }\end{array}$ & 92 & 1.40 \\
\hline 9. & $\begin{array}{l}\text { Pakistan Journal of } \\
\text { Agricultural } \\
\text { Research }\end{array}$ & 91 & 1.38 \\
\hline 10. & $\begin{array}{l}\text { International } \\
\text { Journal of } \\
\text { Agriculture and } \\
\text { Biology }\end{array}$ & 90 & 1.37 \\
\hline
\end{tabular}

\subsection{Most Beneficial Authors}

The study reveals that Singh $S$ is that the most ranking authors of Cotton analysis who revealed 136 papers $(2.07 \%)$ followed by Kranthi K R with 106 papers $(1.61 \%)$. It's observed that out of the highest five authors who contributed a lot of papers in Cotton Crop analysis, there are world ranking author contributed a paper level of 42 to 136 viz., Kranthi S, and Balasubramanya R H, 99 papers $(1.51 \%)$ and 98 papers (1.49\%), are equally published articles and Venugopalan M V 97 Papers $(1.48 \%)$. Table -5 lists the highest 10 ranking authors within the field of Cotton Crop analysis.
Table -4. Most Beneficial Authors in Cotton Analysis

\begin{tabular}{|c|l|c|c|}
\hline Sl.No. & Name of Author & $\begin{array}{c}\text { No. Of } \\
\text { Papers }\end{array}$ & Percentage \\
\hline 1. & Singh S & 136 & 2.07 \\
\hline 2. & Kranthi K.R & 106 & 1.61 \\
\hline 3. & Kranthi S & 99 & 1.51 \\
\hline 4. & $\begin{array}{l}\text { Balasubramanya } \\
\text { R.H }\end{array}$ & 98 & \\
\hline 5. & Venugopalan M.V & 97 & 1.49 \\
\hline 6. & Blaise & 94 & 1.43 \\
\hline 7. & Kumar S & 66 & 1.01 \\
\hline 8. & Kumar A & 47 & 0.72 \\
\hline 9. & Khadi B.M & 45 & 0.69 \\
\hline 10. & Sangwan R.S & 42 & 0.64 \\
\hline
\end{tabular}

\subsection{Language Distribution}

It is observed that English is the most predominant language used by the researchers for communication in the Cotton Crop analysis [5] with 5,673 papers $(86.08 \%)$ followed by Chinese with 369 (5.60) and Portuguese with 233 (3.54\%). The top 10 predominant languages are furnished in Table -6 .

Table -5. Language Distribution of Cotton Analysis

\begin{tabular}{|c|l|c|c|}
\hline Sl.No. & \multicolumn{1}{|c|}{ Language } & $\begin{array}{c}\text { No. of } \\
\text { Papers }\end{array}$ & Percentage \\
\hline 1. & English & 5673 & 86.08 \\
\hline 2. & Chinese & 369 & 5.60 \\
\hline 3. & Portuguese & 233 & 3.54 \\
\hline 4. & Turkish & 77 & 1.17 \\
\hline 5. & Spanish & 68 & 1.04 \\
\hline 6. & Persian & 59 & 0.90 \\
\hline 7. & French & 45 & 0.69 \\
\hline 8. & Arabic & 22 & 0.34 \\
\hline 9. & Thai & 19 & 0.29 \\
\hline 10. & Bulgarian & 14 & 0.22 \\
\hline
\end{tabular}

\section{Findings}

These are the findings of the Scientometric study and it is hoped this finding is likely to be helpful 
for the stakeholders of Cotton analysis knowledge managers in these areas:

- Indian contribution to global Agricultural research based on $\mathrm{CAB}$ Direct Online database revealed that India has published 6,591 papers in various fields of cotton analysis.

- $\quad$ Singh $S$ is that the most ranking authors of Cotton analysis who revealed 136 papers (2.07\%) followed by Kranthi $\mathrm{K} \mathrm{R}$ with 106 papers $(1.61 \%)$.

- Most preferred journals are: Journal of Cotton Research and Development with 954 papers $(14.48 \%)$ followed by the International Journal of Plant Protection with 126 papers $(1.92 \%)$.

- India is the top country in Agricultural research, with its contribution of 2,177 papers which is nearly $(33.03 \%)$ of the global research output of Agricultural research followed by the specific country are in Pakistan, with 414 papers $(6.29 \%)$ ranks second position, with 246 papers $(3.74 \%)$ in is a third position.

\section{Conclusions}

During these years (1976-2018), of time duration typical duty in conveyances is basically prolonged within the area of cotton examine. An examination of the cotton trim asks approximately yield is a count of Mean Absolute Deviation (M.A.D) of as a rule setting apart the inventive work in the subject [2]. Where $\Sigma$ is an aggregate number of research output: information value acquired from mean partitioned by number of regards. The cotton inquire about yield, obviously the period has 1980 , 1987, 1995, 1997 and 1998 has less yield of research in that period, anyway bit by bit growing example estimation of that explicit period on but slowly increasing trend value of that particular period on 2001-2007 but slowly increasing trend value of that particular period on 2001-2007. The India is the best country in cotton survey, with its dedication 6,591 papers of the overall research yield of Agricultural research out of this the specific country in Asia are in Pakistan with 414 papers $(6.29 \%)$. An Indian researcher ought to be the cotton investigate field so the dedication of India in this examination locale could be in a general sense extended.

\section{References}

[1] Sozon Papavlasopoulos, Scientometrics Analysis in Google Trends, Journal of Scientometric Research, Vol 8 (Issue 1): 27-37, (2019).

[2] Gupta B.M and Dhawan S.M, Robotics Research in India: A Scientometric Assessment of Indian Publications Output during 2007-16, Journal of Scientometric Research, Vol 7 (Issue 2): 84-93, (2018).

[3] Rajendran Lakshmanan, A Scientometric Mapping of Research on Leptospirosis Diseases, International Journal of Advanced Scientific Research and Management, Vol 3 (Issue 9): 148-153, (2018).

[4] Ritu Gupta, Dhawan S.M and Gupta B.M, World Rabies Research Output: A Scientometric Assessment of Publication Output during 2006-15, Journal of Scientometic Research, Vol 5 (Issue 3): 220229 (2016).

[5] Kumaravel J.P.S. Pricilla Rani. P and Kalai Selvi S, Transient and continuant authors in robotic medicine: A scientometric view, Journal of Scientometric Research, Vol 2 (Issue 3): 202-205, (2013).

[6] Rajendran Lakshmanan, World Research Publications on Potato (Solanum Tuberosum): A Scientometric Assessment. Asian Journal of Information Science and Technology, Vol 8 (Issue 2): 32-35, (2018).।

[7] https://www.nfsm.gov.in/BriefNote/BN_Cotton.pdf 